\title{
هل يقع النقل الجمازي في الألفاظ الشرعية؟
}

\section{*المصطفى تاج الدين}

\section{تمهيد}

اختلف الأصوليون واللغويون في طبيعة تعامل الشارع الحكيم مع اللغة، هل أبقى الألفاظ اللغوية على دلالتها الأصلية، أم تصرف فيها بنقلها لتدل على معان شرعية جديدة أم بين هذا وذاك.

وذهب المعتزلة إلى القول بأن الشرع يتصرف في الألفاظ تصرف الواضع للغة، ولذلك فهو ينقل الألفاظ من معانيها الأصلية نقلاً مطلقاً بحيث لا يبقى لما تعلق من أي وجه بها، وذهب الأشاعرة إلى القول إن النقل الشرعي للألفاظ ليس كلياً، بحيث إن الألفاظ تكون دالة على معانيها اللغوية فيتصرف فيها الشرع تصرفاً آخر بالنقل مع بقاء دلالاتما الأصلية واردة حين التفظ والاستعمال، وتضاف إليها الدلالات الشرعية الجديدة، وهذا مذهب الغزالي، وخالف الباقلاني الجمهور فأبطل النقل جملة،1 وهو ما نراه صواباً كما سيأتي بيان ذلك.

وقد يبدو لمن لم يتعود على التمحيص، واكتفى بالتقليد والمحاكاة، أن أمر الحقيقة الشرعية قد حسم، وأن لا بجال فيها للمتزيد، والحقيقة أن الحلاف بين العلماء ما يزال جذعاً في هذه المسألة، أي في وقوع النقل الشرعي للألفاظ، وفي طبيعته وخصائصه.

ولأهم ربطوا المجاز بالوضع اللغوي2 فإن ما أسموه الحقيقة الشرعية يقف حاجزاً أمام اكتمال بنائهم النظري، لأها تقتضي القول بوقوع وضع تال للوضع الأصلي، إذ مجرد اعتبارها منقولة يدخلها في الحد الذي وضعوه للمجاز، ولأفا ليست مجازاً عند أغلب الأصوليين خلافا للرازي3 والبيضاوي4 فقد عدوها حقيقة

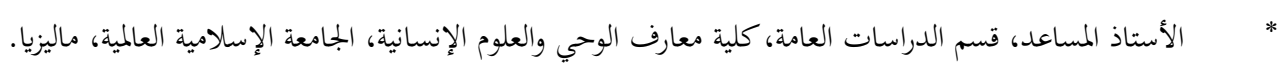

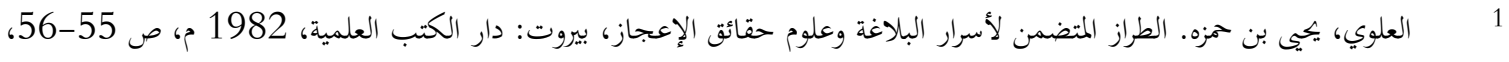

$$
3 \text { 2 } 3
$$


شرعية، ويلزم عنه أن يسلموا بأن الشرع أحدث في الألفاظ وضعاً ثانياً وهذا أيضاً غير مقبول، ويشرح البيضاوي السبب قائلاً: "واختلف في الشرعية، فمنع القاضي، وأثبت المعتزلة، والحق أها بجازات لغوية

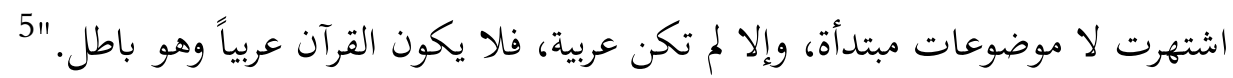

ولقد ذهب بعضهم في إثباتما مذهباً طريفاً، فقد قسم الألفاظ إلى:6

$$
\begin{aligned}
& \text { قسم يكون فيه اللفظ والمعنى معلومين لأهل اللغة غير أفم لم يضعوا الإسم لذلك المعنى؟ } \\
& \text { قسم يكون فيه اللفظ والمعنى غير معلومين كأوائل السور لمن جعلها أسماء. } \\
& \text { قسم يكون فيه اللفظ معلوماً لديهم والمعنى غير معلوم؟ } \\
& \text { وقسم يكون فيه المعنى معلوماً واللفظ غير معلوم كالأب. }
\end{aligned}
$$

وبالنسبة للقسم الثاني فهو كما ترى قسم غريب، وهو على كل حال غير ملزم إلا لمن جعل الحروف المقطعة أسماء، أما القسم الثالث والرابع فأمرها أعجب؛ إذ أن ثنائية اللفظ والمعنى عمقت أخاديدها في وعي بعض اللغويين والفقهاء فأضحوا يسلمون بوجود ألفاظ دون معان ومعاني دون ألفاظ، وليس هذا فحسب بل إن هذا اللفظ عديم المعنى معلوم لديهم، وهذا المعنى يتيم اللفظ معلوم لديهم أيضاً وليت شعري كيف يكون اللفظ معلوماً دون معناه؟ هل يكون حينها لفظاً أم مجرد أصوات؟ وإن كان صاحب التقسيمات يقصد أن أناساً قد يجهلون معنى لفظ متداول عند الجماعة اللغوية فهذا جد وارد، والمسألة هنا جهل بالمعنى

$$
\text { وليس كما يوهم التقسيم وجود ألفاظ معلومة دون معناها. }
$$

ثم ما هذا المعنى المعلوم ذو اللفظ المجهول؟ أهو شيء تجس به الجماعة اللغوية دون أن يجعلوا له لفظاً

$$
\text { يعبرون به عنه؟ وهل عرفوا اللفظ بمجرد أن سمعوه كما في الأب؟ }
$$

\footnotetext{
4 4 السبكي، على بن عبد الكافي. الإبهاج في شرح المنهاج على منهاج الوصول إلى علم الأصول للقاضي البيضاوي، بيروت: دار الكتب

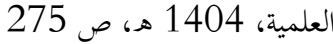

5 6
} 
وأما القسم الأول فقد استشهد عليه صفي الدين الهندي بقوله تعالى: السماواتِ والأرْض ليقُولُن اللهمِ (الزخرف:87) قال: "فإن هذا اللفظ (أي الله) كان معلوماً لديهم... لكن

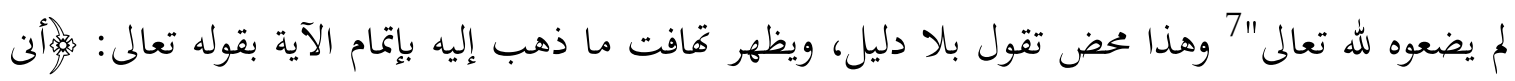
يُوْْفكُونهُ أي كيف يكذبون بأن أخبروا بغير ما يطابق الواقع في اعتقادهم، ولو أفم جهلوا معنى اللفظ لما كان هناك سبب لرميهم بالكذب لأفم سيكونون ساعتها قد أخبروا بشيء لا يعتقدون خلافه. 8 وعموماً فإن الشرع لم يأت ليحدث في اللغة أوضاعاً جديدة، ولا أن يتصرف فيها على غير هدى من سننها وقانوها فلا يتصور إذاً وقوع الوضع الثاني كما لا يتصور أن تنفصل الدلالة الشرعية عن الدلالة اللغوية للألفاظ بحيث تشير الثانية إلى معنى لا تشير إليه الأولى، ولقد تنبه الشيخ عبد القاهر الجرجاني إلى هذا حين قال: "وأقل ما ينغي أن تعرفه الطائفة الأولى وهم المنكرون للمجاز أن التنزيل كما لم يقلب اللغة في أوضاعها المفردة عن أصولما ولم يخرج الألفاظ عن دلالتها وأن شيئاً من ذلك إن زيد إليه ما لم يكن قبل الشرع ما يدل عليه، أو ضمن ما لم يتضمنه أتبع ببيان من عند النبي صلى الله عليه وسلم كذلك لم يقصد بتبديل عادات أهلها، ولم ينقلهم عن أساليبهم وطرقهم من التشبيه والتمثيل والحذف والاتساع." "9 ومعنى ذلك أن ما قام به الشرع بحاه الألفاظ ليس سوى عمليات دلالية تقوم بها الجماعة اللغوية نفسها في تعاملها مع الألفاظ أقصد بهذه العمليات: التخصيص والتعميم والتأكيد وغير ذلك. وسنحاول الآن أن نقوم بدراسة خاصة لبعض الألفاظ التي ادعوا فيها النقل من المعنى اللغوي (الوضعي) إلى المعنى الشرعي (العري).)

الصلاة ذهبوا إلى أن الصلاة في اللغة: الدعاء، واستدلوا على ذلك بقول الأعشى: السبكي، على بن عبد الكافي. الإبماج في شرح المنهاج على منهاج الوصول إلى علم الأصول للقاضي البيضاوي، مرجع سابق، ص 276

$$
\begin{aligned}
& 8
\end{aligned}
$$

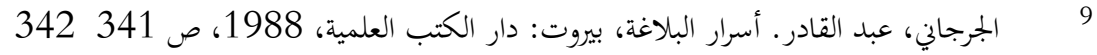




$$
\text { وقابلها الريح في دها }
$$

وهم وإن وجدوا للفظ الصلاة معاني أخر في اللغة، 11 فإن معنى الدعاء هو ما اختاروه ليكون أصلاً تمت على أساسه عملية النقل إلى المعنى الشرعي، ويرى الرازي أن لفظ الصلاة لم يعد يعني معانيه اللغوية،

$$
\text { وعلل ذلك ب: } 12
$$

التبادر: بحيث إذا أطلقنا لفظ الصلاة لم يتبادر إلى الذهن غير المعنى الشرعي الحادث، وهذا التبادر هو مقياس كون اللفظ المنقول حقيقة فيما نقل إليه. أن صلاة الإمام والمنفرد صلاة مع أنه لا يوجد فيها متابعة، ولا يكون رأسه عند ورك غيره. أن صلاة الأخرس صلاة ولا دعاء فيها "فدل على أن هذه اللفظة غير مستعملة في معانيها

والذي ذهب إليه الرازي من انتفاء الدعاء عن صلاة الأخرس عجيب، والكل يعلم أن الأخرس كالكليم في كون صلاته متضمنة قطعا للدعاء.

أما تعليله لنقل لفظ الصلاة من الدعاء بالتبادر، فيعد دليلاً على أن دلالة الصلاة المعروفة متلبسة باللفظ منذ كان، ولم يحدث له نقل البتة، وهذا يكتفي باللفظ حين استعماله، ولا يلجأ للقرائن الخارجية، لأن اللفظ دال على العبادة المعروفة بالوضع الأول على اصطلاح من قال بوضعية اللغة، أو بالاستعمال كما هو مذهبنا في ذلك.

$$
\text { فهل حدث نقل للفظ الصلاة من الدعاء؟ }
$$

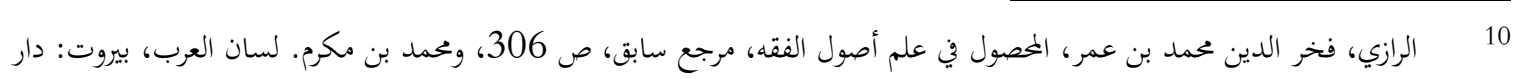

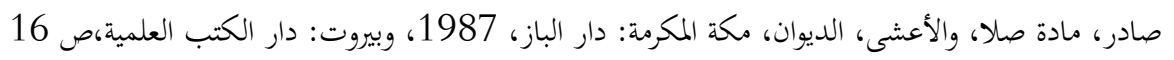

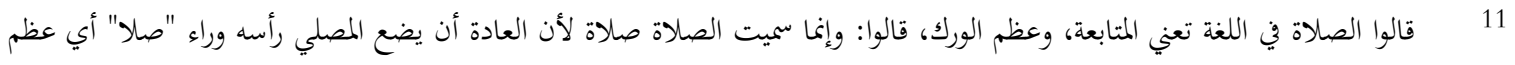

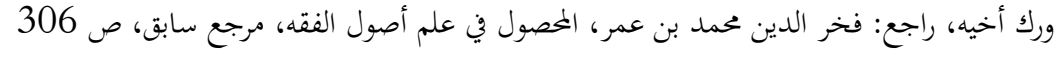

$$
\begin{aligned}
& 12 \\
& \text { المرجع السابق، ص } 307
\end{aligned}
$$


للإجابة على هذا السؤال سنسلك مسلكاً حجاجياً مؤسساً على:

\section{1. القرآن}

إن استقراء لنصوص القرآن في المواضع التي ذكرت فيها الصلاة تبين بوضوح قافت رأي من ذهب فيها إلى النقل.

قال تعالى حكاية عن إبراهيم عليه السلام: فما هي يا ترى هذه الصلاة التي سيقيمها إبراهيم عليه السلام وذريته من بعده؟ أهي الدعاء؟ حتماً كلا لأن الدعاء لا يقام، فاقتضى أن إقامة الصلاة إنما تكون بكيئات مخصوصة وأركان معلومة، قال البيضاوي في الآية:

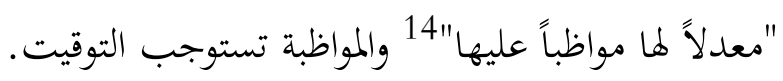

وها هو القرآن الكريم يحدثنا عن ذرية إبراهيم التي سكن فرع منها أكناف الجزيرة العربية، ومشوا في مناكبها، وتكلموا بالعربية، هذه الذرية كانت مقيمة للصلاة، وهي عبادة انتشرت بفعل الدعوة الإبراهيمية، حيث عرفها الناس وأقاموها بركوعها وسجودها وقيامها وميقاتا، وخصوصاً منهم أولئك الذين كانوا يحجون إلى البيت الحرام، فكانت صلاقم وحجهم تصديقا لدعاء خليل الرحم:

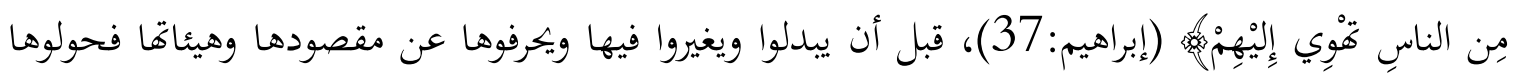
إلى بجرد أصوات تلفظها ألستهم ولا تعيها قلوبهم، أصوات تلهج بذكر آلهة ما لها في الحق من نصيب،

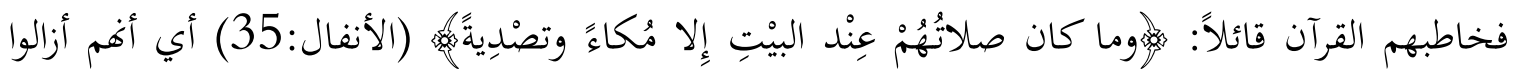
الصلاة عن معناها الإبراهيمي وهو القيام والركوع والسجود وجعلوها مجرد أصوات ودعاء يدعون به آلهتهم الكاذبة، فتأكد أن الأصل في إطلاق لفظ الصلاة أن تراد بها العبادة المخصوصة على الأقل منذ عهد إبراهيم، فمتى حدث النقل يا ترى؟ هل حدث قبل إبراهيم؟ إذا كان ذلك كذلك فأين الدليل؟ أم هو مجرد

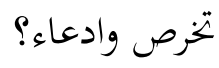


إن المكانة العظيمة التي تشغلها الصلاة في الإسلام لدليل على حرص الشارع عليها، فلم تخل منها شريعة من الشرائع، ولا تميزت بها رسالة من الرسالات.

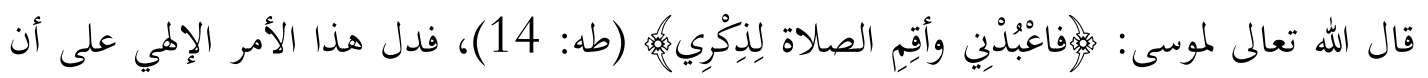
الصلاة بمنزلة عظيمة في كل دين، وأها تأتي مباشرة بعد التوحيد، بل إنا في إقامتها والحرص عليها عين التوحيد ولبه، فأقم الصلاة لذكري معناه أن الصلاة تذكر بعظمة الله وعزته وجبروته، وهذه هي معاني التوحيد، قال البيضاوي: "خصها بالذكر، وأفردها بالأمر للعلة التي أناط بها إقامتها وهو تذكر المعبود وشغل القلب واللسان بذكره، وقيل لذكري: لأني ذكرتا في الكتب وأمرت بها."15 وقال القرطبي: "وقيل المعنى أي حافظ بعد التوحيد على الصلاة، وهذا تنبيه على عظم قدر الصلاة إذ هي تضرع إلى الله تعالى وقيام بين يديه. "16

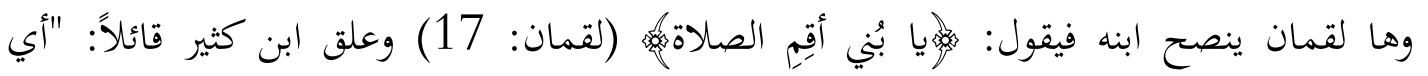
بحدودها وفروضها وأوقاتا."

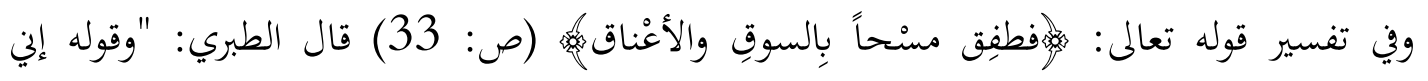
أحببت حب الخير من ذكر ربي حتى توارت بالحجاب، وفي هذا الكلام محذوف استغنى بدلالة الظاهر عليه من ذكره، فلهي عن الصلاة حتى فاتته"18 وفي كلام الطبري ما يفيد أن الصلاة كانت في عهد سليمان لميقات معلوم، وإنما لام نفسه لا لنسيان ذكر الله مطلقاً، بل لأنه نسيه في لحظة حتى مضى وقت الصلاة، وذهب البغوي إلى أنه أمر بالجياد فأرجعت حتى صلى العصر في وقتها. 19

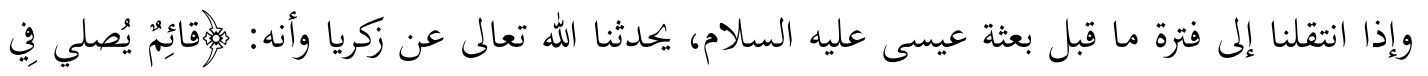
المِحْرابه. (آل عمران: 39) فماذا يفعل هذا النبي في المحراب سوى إقامة الصلاة، ومريم التي خاطبها الله

$$
\begin{aligned}
& 15 \\
& 1617 \\
& 17 \text { } 17 \\
& 1818
\end{aligned}
$$

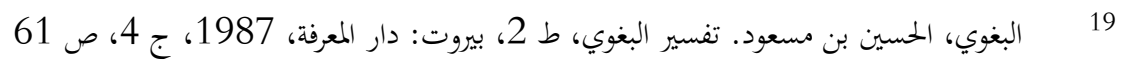




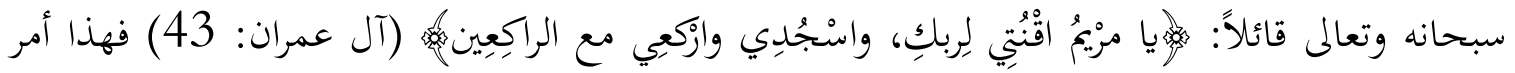

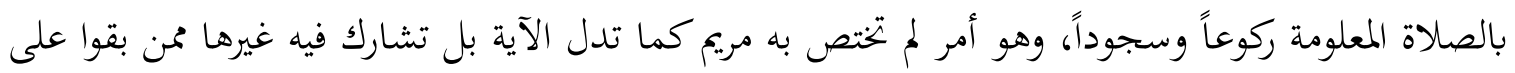

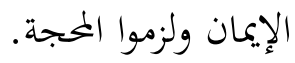

ومن نكت هذه الآية مما بدا لنا أن مريم إذل متكن رسولة فهي لم تؤمر بتبليغ هذا الأمر بالصلاة مما

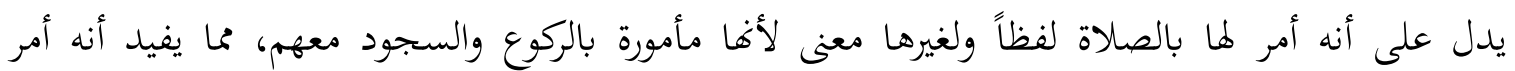
يفعلونه، فخرج عن كونه أمراً ابتدائياً بالصلاة إلى كونه أمرا بلزومها والمواظبة عليها.

وهو إعلام من الله أن الناس في زمن مريم كانوا يصلون الصلاة المعهودة منذ إبراهيم وربما قبله، فأمر

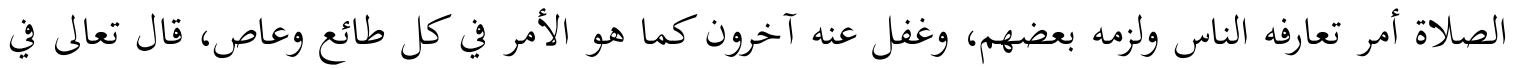

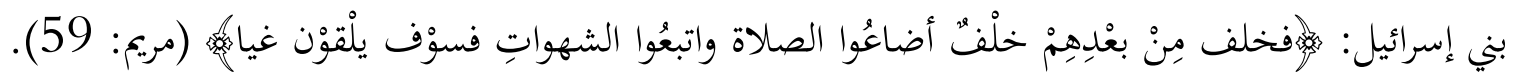
وما أحدثه الإسلام في الصلاة هو ما أحدثه في الدين كله: تتميم وإكمال وهيمنة وليس إنشاء وإبداعاً:

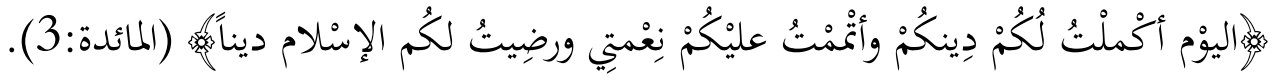

فمتى حدث نقل للصلاة من الدعاء؟ لا شك أن متمسكهم سيكون زعماً بأن النقل وقع في زمن ما

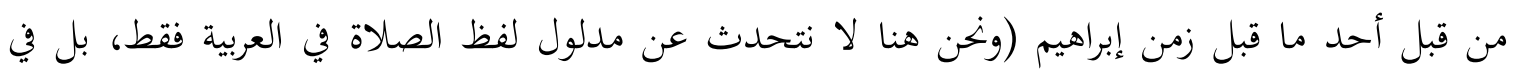

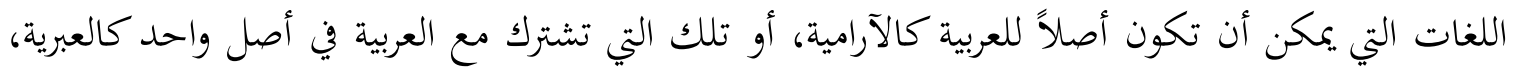

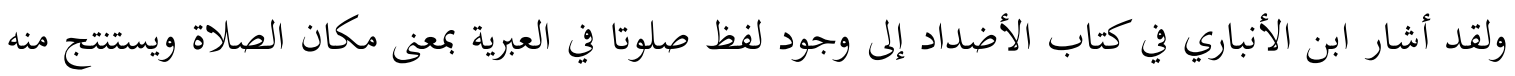
أن الأصل الذي اشتق منه اللفظ الدال على مكان الصلاة لا يبعد في حروفه عن الفرع المشتق منه، وهو أصل الصاد واللام) وهو أمر سيخرجوه أيضاً بغربال العقل واسع الثقوب، فيقولون: إن ذلك ملما يجوزه العقل ولا يستنكره، إذ هو داخل في دائرة الإمكان والجواز.

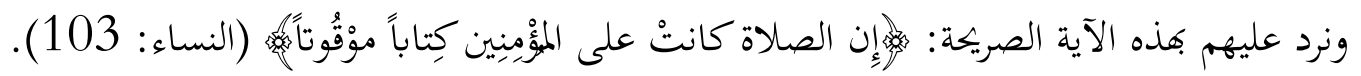

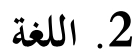


سنحاول هنا أن نتناول الآية السابقة من منظور لغوي حتى يتم لنا بيان وجه اعتراضنا بها فقد اختلف النحاة في دلالة "كان"20 في العربية فذهب بعضهم إلى أها تفيد الانقطاع والتجدد، أما ابن معط في ألفيته فقد جزم بأها تقتضي الدوام والاستمرار قال: "وكان للماضي الذي ما انقطعا. 21 ونخن وإن كنا لا نقول بالمذهبين فإن خلافهما لا يتطرق بتأثير إلى ما نحن بصدد إثباته من دلالة كان على الماضي غير المحدد، إذ الحلاف بين المذهبين في دلالة كان على الاستمرار فقولك: كان زيد صديقي، يدل عند ابن معط على الاستمرار وعدم الانقطاع وأن زيداً ما يزال صديقك إلا أن تستدرك فتقول: ولم يعد الآن. أما على مذهب من يرى في كان دلالة على الانقطاع ففي قولك: كان زيد صديقي، دليل كاف على

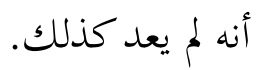

وذهب آخرون إلى أن كان "عبارة عن وجود الشيء في زمان ماض على سبيل الإعام، وليس فيها دليل على عدم سابق ولا على انقطاع طاريء"22 قاله الزخشري.

والذي نذهب إليه هو تخليص مبحث كان من سياقاته العقدية، ومتى ورد في سياق عقدي معين تلبس بحكم السياق ومقتضى الخطاب، ولذلك ذهب ابن عطية في تفسيره إلى أها "حيث وقعت في صفات

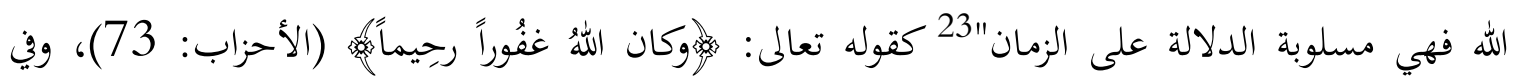
المقابل فإها تتعلق بالزمان لتفيد الانقطاع في قولك: "كان أبوك صالحا"، وإفادة الانقطاع هنا ليس دلالة ذاتية في "كان" بل تفيده بناء على قصد المتكلم. ألا تراك في سياق مدح أبيه فيما فعله في ماضيه تقول: "كان أبوك صالحا" وأنت لا تعني أنه لم يعد كذلك، ولا تقصد تعريته من الصلاح حال حديثك عنه فليتأمل.

ولعلك خارج بخلاصة أن حديثهم عن "كان" متلبس بسياقات ورودها، وإفرادها بحكم مشكل.

$$
22 \text { 22 } 20 \text { } 20
$$


وفي الآية مناط الاستدلال قال منصور بن فلاح اليمني في "كان": " قد تدل على الدوام بحسب القرائن، كقوله:

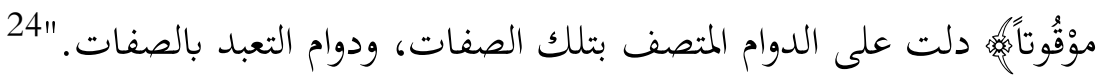
وهذه الآية هي في معنى قوله تعالى: الإخراج هنا إخراج كلي متعلق بكل من آمن وتحقق بمعنى الإخراج، وقصره على الأمة المحمدية فيه نظر، لأن

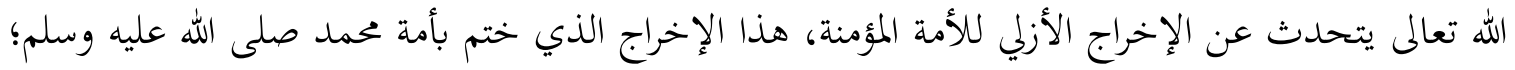
لأن فعل كان يفيد الاستغراق في الزمن الماضي وهو زمن مبهم لا تعرف له بداية سوى بداية الأمر بالتكليف.

ولا يبدو في كلام القوم تيقن أن الصلاة تدل في اللغة على الدعاء، ولا إجماع في ذلك كما يتوهمه البعض، قال صاحب التعاريف: "الصلاة عند المعتزلة من الأسماء الشرعية، واختلف في وجه التشبيه على أقوال، قال الإمام الرازي: والأقرب أها من الدعاء إذ لا صلاة إلا وفيها الدعاء أو ما يجري مجراه، وقال أصحابنا من المجازات المشهورة إطلاق اسم الجزء على الكل فلما كانت مشتملة على الدعاء أطلق اسم الدعاء عليها مجازاً، قال فإن كان مراد المعتزلة من كوغا اسماً شرعياً هذا هو فحق، وإن أرادوا أن الشرع ارتجل

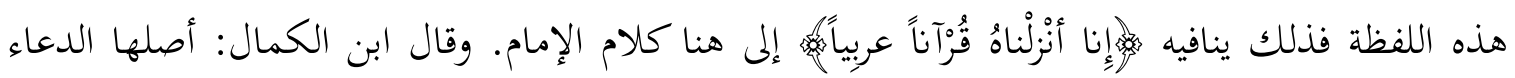
مميت به هذه العبادة التي هي أفعال وأقوال مفتتحة بتكبير مختتمة بتسليم كتسمية الشيء باسم ما يتضمنه والصلاة من العبادات التي لا تنفك شريعة منها وإن اختلفت صورها بحسب شرع وشرع."

فمذهب الأصحاب عند الرازي يدل على أن الأصل هو الصلاة والدعاء مجاز عنها، ذهبوا إلى ذلك لأفم يرون في تصرف الشرع في اللغة بإيقاع أوضاع تالية على الأوضاع الأصلية تعارضا مع عربية القرآن، وهو مذهب أبي بكر الباقلاني، وعليه سار فيما يبدو الشيخ عبد القاهر الجرجاني، أقصد أغما نفيا النقل الشرعي للألفاظ اللغوية، وهو ظاهر مذهب ابن حزم.

$$
\begin{aligned}
& 24
\end{aligned}
$$

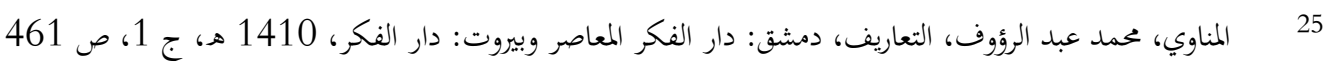




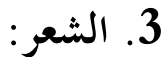

استدل القائلون بكون لفظ الصلاة قد نقل من الدعاء إلى العبادة المعلومة نقلاً شرعياً ببعض أبيات من الشعر الجاهلي ولعل بيت الأعشى هو الدائر على الألسنة في هذا الخصوص. يقول الأعشى:

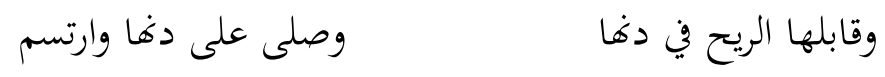

والحقيقة أن الاستدلال بالأعشى هنا يجتاج إلى نظر، إذ أن هناك أدلة عديدة على أن الرجل كان قد تنصر في الجاهلية، وإن لم يكن قد دخل النصرانية بصفة رسمية فلا أقل من أنه قد تأثر بكثير من العقائد النصرانية نجدها ظاهرة في شعره، ولعل لفظ الصلاة الذي أشار إليه من الألفاظ التي نقلها عن النصارى الذين احتك بهم، فتكون دلالة اللفظ عندها دلالة شرعية أصلاً ولم يحدث لها نقل كما زعم الكثير.

ومن الذين أشاروا إلى أن الأعشى كان نصرانياً لويس شيخو في كتابه شعراء النصرانية، 26 ولقد أورد صاحب الأغاني نصوصاً دالة على صلة الأعشى بالأوساط النصرانية قبل مجيء الإسلام فقد روى أحدهم عن يهيى بن متى راوية الأعشى "وكان نصرانياً معمراً، قال: كان الأعشى قدرياً وكان لبيد مثبتاً. قال لبيد:

$$
\text { من مقال الأعشى: }
$$

قلت فمن أين أخذ الأعشى مذهبه؟ قال من قبل العباديين نصارى الحيرة كان يأتيهم يشتري الخمر فلقنوه ذلك."27 وفي رواية أخرى تظهر مدى تأثر الأعشى بالعقائد النصرانية والتي لا نشك في احتوائها على تلى

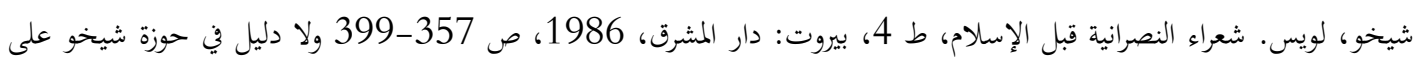
26

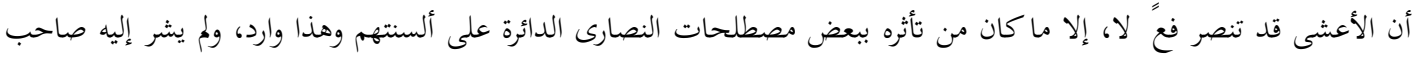

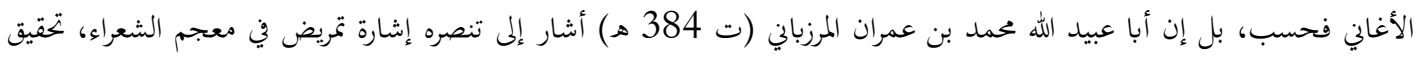

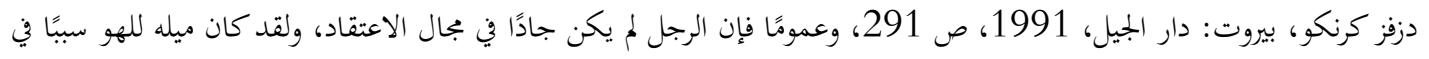

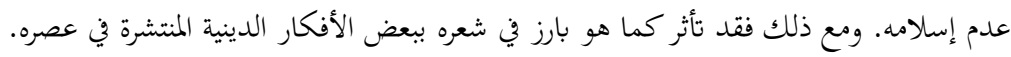

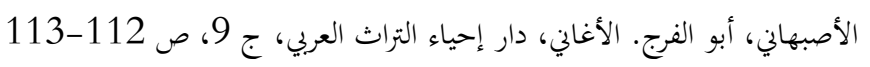


بقايا من العبادات الصحيحة على الرغم مما لحق بالنصرانية من التحريف والتبديل، يقول صاحب الأغاني في ما رواه يونس بن متى أن لبيدا كان ججبراً حيث يقول:

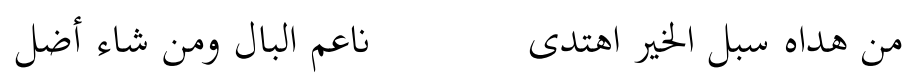

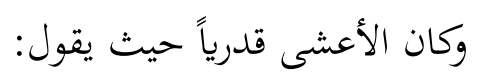

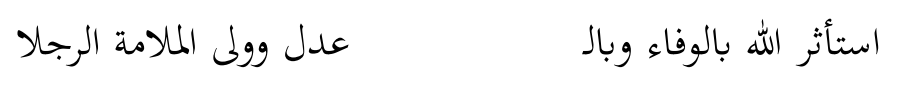

فقلت له: من أين أخذ هذا؟ فقال: أخذه من أساقفة نجران، وكان يعود في كل سنة إلى بني عبد المدان فيمدحهم، ويقيم عندهم، ويشرب الخمر معظم، وينادمهم، ويسمع من أساقفة نجران قولم، فكل شيء في شعره من هذا فمنهم أخذه."

ولو رجعنا إلى شعره لألفينا المعاني الدينية تشير إلى أثر النصرانية في فكر الأعشى يقول في مدح أهل

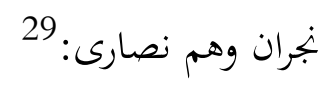

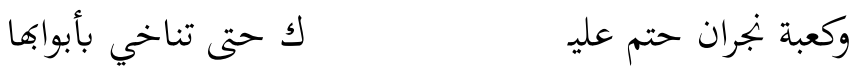

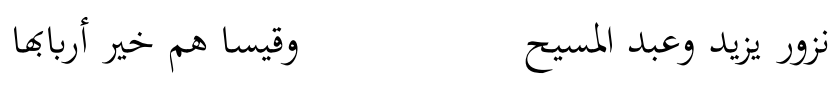

وهنا يظهر لنا أن الأعشى لم يكن بعيداً عن التصورات الدينية التوحيدية المنتشرة في مجتمعه سواء أكانت مثثلة في بقايا الحنيفية الإبراهيمية والإسماعيلية والتي مارست تأثيرها إلى حدود نزول الرسالة الخاتمة، أو كانت بجسدة في الديانات التوحيدية التي كانت معتنقة في جزيرة العرب كالنصرانية واليهودية، فإن كان الأمر كذلك، فإن استعمال الأعشى لفعل "صلى" لم يكن بالمعنى الوضعي الأصلي حتى ندعي أنه نقل بالمجاز إلى المعنى الشرعي، إذ أنه استعمله في إطار الدلالة الدينية نفسها والتي سيأتي الإسلام ليؤكدها ويزكيها عملاً بأصل أن الرسالة الخاتمة جاءت لتتم دين التوحيد، وتكمله، وتصوغه الصياغة النهائية والتي لن تحتاج بعد

$$
28 \text { 28 } 29
$$


ذلك لزيادة أو نقصان، ولو سلمنا جدلاً أن الأعشى استعمل فعل الصلاة بمعنى الدعاء، فإن هذا لن يخدم أصحاب النقل المجازي، إذ سبب هذا الاستعمال سيكون مصدره التحريف الذي أصاب الشعائر التعبدية في النصرانية، فبعد أن دلنا أن الصلاة في دين إبراهيم وعيسى كانت متضمنة للقيام والركوع والسجود والتوجه نهو القبلة صارت بفعل التحريف والتفريط بجرد دعاء يلفظ وهمهمات تردد. فيكون معنى الدعاء إذن طارئاً على الدلالة الأصلية عوض أن يكون هو الأصل.

ولمزيد في التوضيح نقول إن العرب في الجاهلية كانت تعرف الصلاة، وتعرف القبلة، والسجود وغير ذلك، فلم يكن لفظ الصلاة عندها بعيداً عن دلالاته الدينية المنحدرة إليهم من عهد إبراهيم، وربما قبله، ودليلنا على ذلك بيت شعري لعنتره لم يلق الاهتمام الذي يليق به من قبل الأصوليين ولو أعطوه بعض العناية لغيروا بعضاً من آرائهم في الموضوع يقول عنتره مادحاً ملك الفرس كسرى أنو شروان:30

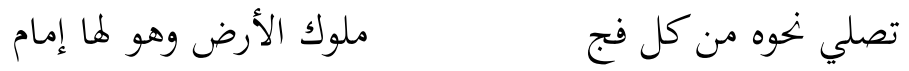

فهل يحتمل بيت عنتره أن نؤول فعل الصلاة فيه بالدعاء؟ إذ لم يكتف الشاعر بأن استعمل الفعل معدى ب"نحو" المشيرة إلى القبلة، بل أضاف كلمة الإمام مما يشير إلى شكل الصلاة الإسلامية على مستوى الشكل، وهو ما لا مزيد فيه لمتزيد يدعي نقلاً بجازياً في مثل هذه الألفاظ.

\section{الصوم}

وذهبوا في الصوم إلى أنه مطلق الإمساك في اللغة، وأضحى في الشرع إمساكا خخصوصاً، 31 والأدلة القرآنية مشيرة إلى أن الصوم إذا أطلق أفاد العبادة المخصوصة، ودلالة مطلق الإمساك دلالة تفرعت عن الدلالة التي استعمل فيها الشرع الكلمة، فحدث تعميم

$$
31 \text { 30 } 30
$$




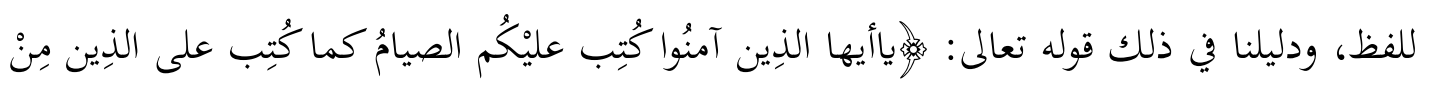

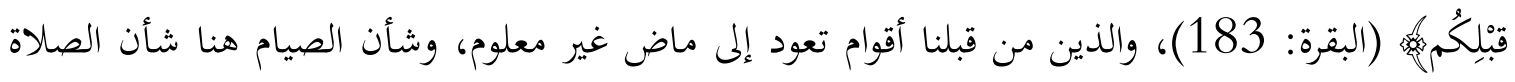
في كونه أمراً إلهياً غير معلوم البداية، ولا يبعد أن الناس أمروا به منذ أن أمروا بالتكليف وتحمل الأمانة.

وذهب الرازي إلى أن ما يتبادر إلى الذهن حين إطلاق اللفظ هو العبادة المخصوصة، وهذا عنده دليل على أن الشرع نفله من معناه اللغوي، ونرد على ما ذهب إليه الرازي من وجهين:

أن التبادر مقياس الحقيقة التي هي أصل الألفاظ في الاستعمال، فيكون هذا دليلاً على أن كلمة الصوم تدل على ما تدل عليه بالتبادر لأنه هو المعنى الأصلي، وأما مطلق الإمساك فيحتاج إلى قرينة لحمل اللفظ عليه فهو إذاً فرع عن أصل، وإلا ما كان محتاجاً إلى عامل خارجي في الدلالة. فيكون مطلق الإمساك دلالة حادثة بالتوسع والتعميم.

إن المعنى المتبادر من اللفظ غير مطرد، إذ هو مبني على افتراض مستمع مسلم، ولو كان المستمع غير مسلم كأن يكون من العرب المشركين ما فهم من اللفظ ما فهمه المسلم.

فالذي يقوم به الشرع ليس نقل الألفاظ عن معانيها الأصلية، بل هو التخصيص والتعميم والتوسيع أو ما أشبه ذلك من العمليات الدلالية التي تستظهر بالمقام والسياق والأعراف، وهي عوامل خارجية عن اللغة ذاتما.

ولقد تنبه الجويني إلى هذا فذهب إلى أن تعامل الشارع مع اللغة محصور في بجال التخصيص والتعميم ف" الدعاء التماس وأفعال المصلي أحوال يخضع فيها لربه عز وجل ويبغي بها التماساً، فعمم الشرع عرفاً في تسمية تلك الأفعال تجوزاً، واستعارة، وخصص اسم الصلاة بدعاء مخصوص فلا تخلو الألفاظ الشرعية من هذين الوجهين، وهما متلقيان من عرف الشرع."32"

وليس لأحد أن يتعلق بقشة هذا النص للجويني، وكأنه عثر على ضالته في إثبات المجاز، ولسان حاله يقول: انظر ها هو الجويني لم يكتف بأن قال بالمجاز حتى قال بالاستعارة أيضاً، والاستدلال هذا النص هنا 
ساقط، إذ مهما بلغ الإمام الجويني من العلم في الأصول -وهو بلا شك إمام في ذلك- فليس حجة في اللغة، ومعلوم أن اللغة يحتج فيها بأصحابها أو بمن شهد له بأهلية الاحتجاج به في اللغويات من الفقهاء كالشافعي مثلاً، ونخن نعلم أننا مأمورون بخلع جبة التقليد، وإزاحة غشاوته من على الأعين، وأن نعرف الحق بدليله لا بالرجال.

والتجوز الذي قصده الجويني هنا ليس المجاز المصطلح عليه والذي هو محل خلافنا مع من أثبته، ولو كان قصد الجويني من التجوز ما اصطلح عليه المتأخرون بالمجاز لكان التخصيص والتعميم طريقين من طرق المجاز الاصطلاحي، وهذا ما لم يقل به أحد لأن التخصيص والتعميم مباينان لحد النقل الموجود في البماز. والاستعارة التي قصدها الإمام هنا ليست من الاستعارة المصطلح عليها في قليل ولا كثير، وإنما عنى هما العارية بحيث يستعار جزء من دلالة اللفظ بغرض التعميم، ولو ذهبنا في هذا مذهب المطعني للزمنا أن ندخلهما في المجاز وهذا مخالف لما عليه القوم في الحقيقة الشرعية لسببين: إن القول بمجازية الألفاظ الشرعية يخرجها من دائرة الحقائق، والحال أها حقائق فيما دلت عليه. إن القول بمجازية الألفاظ الشرعية يؤدي إلى الاعتقاد بأها انصرفت عن الإشارة إلى معانيها الأصلية بفعل النقل المجازي، وهذا إن صح في بعض الألفاظ -على اصطلاحهم- فلا يصح في ألفاظ الشرع؛ إذ تبقى دلالاتحا اللغوية مرادة بعد النقل، قال الجويني: "ومن قال إنها نقلت نقلاً كلياً فقد زل، فإن في الألفاظ الشرعية اعتبار معاني اللغة من الدعاء والقصد والإمساك في الصلاة والحج والصوم، فهذا حاصل في

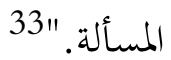

\section{الحج}

الحج في اللغة القصد، وفي الاصطلاح الشرعي القصد إلى مكان مخصوص -البيت الحرام- لأداء فرائض معلومة، وليس فيه نقل من اللغة إلى الشرع كما زعموا في ذلك، وإنما هو تخصيص لمطلق القصد بدلالة خارجية عن اللغة، وليس فيه متمسك لأصحاب النقل، لأن الدلالة الشرعية ليست دلالة لغوية 
حادثة بعد النقل ولكنها دلالة سياقية مقامية، ألا ترى أن العربي المسيحي إذا أطلق لفظ الحج لم يرد به ما يريد العربي المسلم منه، إذ المقصود به عنده التوجه إلى مكان العبادة على مقتضى عقيدته، وليس الحج إلى الكعبة لأداء المناسك.

وللشاطبي رأي في غاية الأهمية يلخص لنا بالضبط ما نريد إثباته في هذه الدراسة، يقول في تفسير قوله

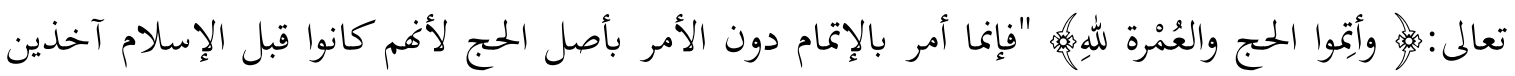
به، ولكن على تغيير بعض الشعائر، ونقص جملة منها، كالوقوف بعرفة وأشباه ذلك مما غيروا، فجاء الأمر

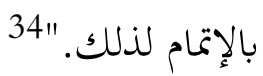
لامستم:

وذهبوا في لفظ "لامستم" مذهباً عجيباً إذ جمعوا في دلالنه بين الحقيقة والمجاز، فقالوا: إن للفظ حالتين: الأولى تكون فيها دلالة اللفظ على جميع معانيه حقيقة. الثانية يكون دلالة اللفظ فيها على بعض المعاني حقيقة وعلى بعضها مجازاً. 35 وهذا قسم جديد من أقسام المجاز يضاف في غرابته إلى قسم الألفاظ التي ليست حقيقة وليست مجازاً، وهذا القسم يكون اللفظ فيه دالاً من جهة على الحقيقة ومن جهة على المجاز، وهو قسم إن صح وقوعه في الألفاظ فإنه يؤدي إلى إفساد الحد الذي وضعوه للمجاز، أي استعمال اللفظ في غير موضوعه، بحيث يشير اللفظ في المجاز إلى دلالة يعرف المستمع والمتكلم أها مرادة بقرينة تحف سياق الكلام أو تركيبه. فانظر كم بلغ تقولم على اللغة، كأن اللافظ إذا نطق بكلمة أراد بها الشيء وقسيمه، وبهذا تفسد أنواع المخاطبات، ويتوسع الناس في اعتبار الكلام دون نظر إلى قصد المتكلم، وفي سياق تفسير القرآن تحمل

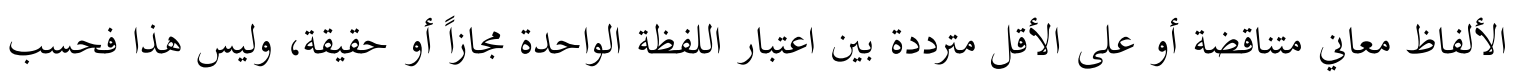

$$
\begin{aligned}
& 34 \\
& 35
\end{aligned}
$$


بل إن مثل هذه الآراء تسمح بأن تدل اللفظة الواحدة على معنيين متعارضين دلالة، ويصح حملها عليهما في آن واحد. وهكذا يخرج القرآن من حد البيان الحاسم للشبهة، إلى حد الغموض والإبهام.

ولقد أوقعهم في مثل هذه المآزق ما نسميه ظاهرة إسقاط المحاور المعرفية على بعضها البعض في التراث، وفيما نحن بصدده حدث لهم إسقاط محور الفقه على محور اللغة.

ومعنى ذلك أن من ذهب في لفظة "لامستم" مذهب الشافعي حمل اللفظ على الحقيقة والمجاز لا لشيء إلا لأن المذهب يقتضي ذلك، وهذا الرأي مصدره المذهب الفقهي لا اللغوي، إذ فهموا من كلام الإمام الشافعي أن "لامستم" محمول على اللمس باليد حقيقة وعلى الوقاع مجازاً، وهو ما جعل الجويني يدخله في جملة المشترك، ويرد على المخالفين بأغم لم يفرقوا "بين أن يكون اللفظ حقيقة في محامله، وبين أن يكون حقيقة في بعضها مجازاً في بعضها"، 36 وهذا المذهب لم يستسغه الباقلاني فذهب إلى أن الجمع في لفظ واحد بين الحقيقة والمجاز جمع بين النقيضين. 37

والذي نراه هنا أن صيغة الفعل هي التي تحدد معناه، وهي صيغة تدل على المشاركة38 في اللمس بين الرجل والمرأة سواء بجماع أو بغيره، وحمل على الجماع بالدلالة القصدية، وهي كناية وليست مجازاً على سلى التحقيق. ولا يضر هنا قراءتنا ب: "لمستم" إذ مقتضاها حقيقة اللمس باليد وغيرها بغرض التلذذ وغير التلذذ على مذهب الشافعي، وتحمل على اللمس بغرض التلذذ عند غيره لا لعارض لفظي، ولكن للحكم الفقهي المبني على الدلالة القصدية، وهي دلالة منتزعة من السياق.

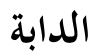

36

37 38

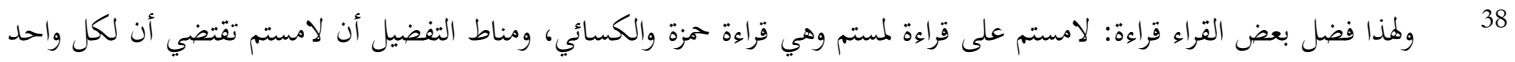

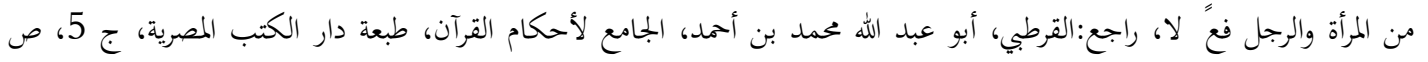


ذهب بعض العلماء إلى أن استعمال الدابة في ذوات الأربع بجاز، والحاصل فيه كما قال الجويني أنه تخصيص، قال: " يخصص العرف أسماء بعض المسميات، ووضع الاسم يقتضي ألا يختص. ثم يقال: فلان

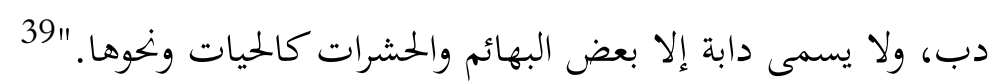

يتحدث الإمام الجويني هنا عن التخصيص وهو عملية مباينة للنقل، ولا يقتضي التخصيص وضعاً مستأنفاً بل هو إيقاع اللفظ على جزء خاص من معناه. ويدل كلام الجويني على أن اللفظ بقي متعاوراً بين البهائم والحيات، وهو عند البعض خاص بالبهائم ذوات الأربع، ثم إنه في عرف جماعات لغوية اليوم إذا أطلق أريد به السيارة، وإنما سميت كذلك لا لنقل حصل، بل بالنظر إلى عموم الدلالة في اللفظ، وإجرائها على بعض أفراد هذا العموم، وهو التخصيص بلفظ الجويني.

\section{خلاصة البحث}

من الواضح لدى أهل الاختصاص أن فهم المصطلحات على حقيقتها اللغوية يعود إلى معهود العرب في استعمالها، وليس إلى تداولها بين أهل الاختصاصات المختلفة، ذلك أن للمصطلحات حياة كحياة الأفراد، تعيش وتنمو بقدر حاجة الناس إليها لقضاء مآركم، ومع نموها يحصل تغير في ملامعها قد ينقلها عن أصول استعمالها، فتكتسب دلالات جديدة حملها إياها أهل الاختصاص. ولذلك ذهب صاحب الطراز إلى أن الألفاظ المشهورة ينبغي أن تحمل على معانيها المعروفة لدى العربي، وليس على معانيها المتداولة عند الخواص، فلفظ الحركة يدل على التحرك وحيث أطلقه العربي فهو يفيد ذلك، أما المتكلمون فإفم قالوا: الحركة لا توضع إلا على معنى يوجب كون الذات متحركة استناداً إلى رأيهم في العلة والمعلول، ولذذا: "فلفظ الحركة متداول بين الجمهور من أهل اللغة، فلا يجوز وضعه إلا على المفهوم عندهم عند إطلاقهم دون ما

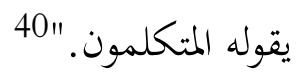

وهذا الذي ذهب إليه العلوي فصل فيه الإمام الشاطبي، وانتهى فيه إلى قانون في تأويل النصوص وتفسيرها، مقتضاه أن ينبني التفسير والتأويل على معهود العرب في كلامهم ومهيعهم في مخاطباتم، وهذا

$$
\begin{aligned}
& 39
\end{aligned}
$$

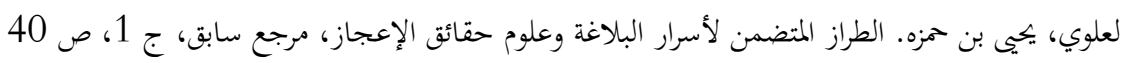


المنهج كفيل بمحاربة الإسقاط والذي يوقع فيه حمل الألفاظ على معاني اصطلاحية اتفق عليها قوم إما لاتفاقهم في مذهب، أو اجتماعهم على هدف أو غاية، فتقوم المصطلحات بتوسيع دائرة الخلاف بين أهل النظر من الطوائف المختلفة مع أها نحتت من أجل تقريب المفاهيم وتسهيل فهمها.

ولعلنا نستطيع أن نؤكد أن هذا الإسقاط المصطلحي هو ما وقع فعلاً لمصطلح المجاز، إذ حمله بعضهم على معهود العرب في استعمال المفهوم، وحمله بعضهم على مقتضى المواضعة الجديدة فذهبوا به مذاهب

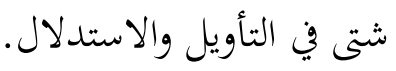

وسنحاول في بحث آخر تم إنجازه بحمد الله أن نقوم بعملية تتبع لمصطلح المجاز منذ نشأته حتى استقواء عوده، وسنبين بحول الله كيف أن المصطلح وإن حمل على دلالثه الاصطلاحية الجديدة، فإن العلماء ظلوا يستعملونه بدلالته اللغوية الأصلية، مما يفيد أن زعم البعض بوجود المجاز الاصطلاحي الدائر حول مفهوم النقل في المراحل المبكرة جداً من تاريخ الفكر اللغوي العربي، زعم قاد إليه الجهل بأوجه استعمال المصطلح عند القدماء. وإذا اتفقنا على أن الدلالة الاصطلاحية التي أنتجها العرف الخاص إن لم تكن خاطئة فهي غير ملزمة للجميع فإننا سنكون حينها ملزمين بإعادة الحياة للمعاني اللغوية الأصلية التي دل عليها المصطلح، خصوصاً إذا أقمنا تعالقاً بين هذه الدلالات اللغوية الأصلية وبجال استخدام المصطلح عند كثير من علماء اللغة والأصول والتفسير. 